Tropical Journal of Pharmaceutical Research May 2019; 18 (5): 1001-1007

ISSN: $1596-5996$ (print); 1596-9827 (electronic)

(C) Pharmacotherapy Group, Faculty of Pharmacy, University of Benin, Benin City, 300001 Nigeria.

\title{
Optimized models of xenobiotic-induced oxidative stress in HepG2 cells
}

\author{
Yollada Sriset ${ }^{1}$, Waranya Chatuphonprasert ${ }^{1,2}$, Kanokwan Jarukamjorn ${ }^{1 \star}$ \\ ${ }^{1}$ Research Group for Pharmaceutical Activities of Natural Products using Pharmaceutical Biotechnology, Faculty of \\ Pharmaceutical Sciences, Khon Kaen University, Khon Kaen 40002, '² Faculty of Medicine, Mahasarakham University, \\ Mahasarakham 44000, Thailand
}

*For correspondence: Email: kanok_ja@kku.ac.th; Tel/Fax: +66-43-202379

Sent for review: 19 January 2019

Revised accepted: 24 April 2019

\begin{abstract}
Purpose: To evaluate the molecular impact of ethanol, sodium selenite, and tert-butyl hydroperoxide (TBHP) on oxidant-antioxidant balance in HepG2 cells to establish an optimized oxidative stress model of HepG2 cells.

Methods: HepG2 cells were treated with ethanol (10 - $500 \mathrm{mM})$ and sodium selenite (1 - $10 \mu \mathrm{M})$ for 24 and $48 h$ and with TBHP (50 - $200 \mu M)$ for 3 and $24 h$, respectively. Biomarkers for cellular injury, ie, lactate dehydrogenase $(L D H)$, aspartate aminotransferase (AST), alanine aminotransferase $(A L T)$, and malondialdehyde (MDA), and for antioxidant system, i.e., superoxide dismutase (SOD), catalase (CAT), and total glutathione content, were determined.

Results: All treatments increased the levels of $L D H, A S T, A L T$, and MDA but decreased SOD and CAT activities and the total glutathione content in HepG2 cells. Oxidative stress was induced by these oxidative stressors in HepG2 cells via oxidant-antioxidant imbalance, with TBHP $(100 \mu \mathrm{M}, 3 \mathrm{~h})$ acting as a powerful oxidant based on the minimal time to induce oxidative stress. The antioxidants, ascorbic acid and gallic acid, improved oxidant-antioxidant imbalance against xenobiotic-induced oxidative stress in HepG2 cells.

Conclusion: These oxidative stress models are suitable for investigating the antioxidant and/or hepatoprotective potential of chemicals, including natural compounds.
\end{abstract}

Keywords: Ethanol, Sodium selenite, Tert-butyl hydroperoxide, Oxidative stressor, Oxidant-antioxidant balance

This is an Open Access article that uses a fund-ing model which does not charge readers or their institutions for access and distributed under the terms of the Creative Commons Attribution License (http://creativecommons.org/licenses/by/4.0) and the Budapest Open Access Initiative (http://www.budapestopenaccessinitiative.org/read), which permit unrestricted use, distribution, and reproduction in any medium, provided the original work is properly credited.

Tropical Journal of Pharmaceutical Research is indexed by Science Citation Index (SciSearch), Scopus, International Pharmaceutical Abstract, Chemical Abstracts, Embase, Index Copernicus, EBSCO, African Index Medicus, JournalSeek, Journal Citation Reports/Science Edition, Directory of Open Access Journals (DOAJ), African Journal Online, Bioline International, Open-J-Gate and Pharmacy Abstracts

\section{INTRODUCTION}

The liver plays a key role in detoxification, including the regulation of physiological homeostasis hence, damage to this organ results in bodily dysfunction [1]. Toxic compounds are among the most pivotal causes of liver toxicity due to the generation of free radical byproducts, especially reactive oxygen species (ROS) [2]. Imbalance in oxidant-antioxidant systems leads to oxidative stress, which is harmful to cells, tissues, and organs and is associated with diseases, e.g. liver diseases [2].

Xenobiotic exposure is an exogenous factor that account for most ROS generation [3]. Examples 
of such xenobiotics include ethanol and sodium selenite, which may be introduced through the diet and lifestyle, and tert-butyl hydroperoxide (TBHP), which is typically related to industrial air pollution [4]. Although these xenobiotics have been used as oxidative stress stimuli, causing hepatotoxicity [5-7] via the induction of cellular oxidative stress [8-9], neither the concentrations nor the trial intervals were optimized in these previous studies.

To understand the mechanism of oxidative stress in the liver, a human hepatoma (HepG2) cell culture has been employed as a liver model due to its reproducible manageability and its similarity in features and functions to human hepatocytes [10]. However, most preliminary studies reported the use of only one or two concentrations of substances to induce oxidative stress in HepG2 cells, without validation of the doses and duration of the treatments. Furthermore, previous reports focused on only one oxidative stressor without comparison with others [7-9]. Therefore, the present study aimed to evaluate the cellular impacts of ethanol, sodium selenite, and TBHP on the oxidant-antioxidant balance in HepG2 cells and to optimize the concentrations and trial intervals of these potential inducers to establish a definitive HepG2 cell oxidative stress model. Moreover, the oxidative stress-inducing capacity of ethanol, sodium selenite, and TBHP was assessed.

\section{EXPERIMENTAL}

\section{Chemicals}

Sodium selenite, tert-butyl hydroperoxide (TBHP, $70 \% \quad w / v)$, sodium pyruvate, 2,4dinitrophenylhydrazine (DNPH), 5,5'-dithiobis(2nitrobenzoic acid) (DTNB), nitroblue tetrazolium (NBT) were purchased from Sigma-Aldrich Chemical (St. Louis, MO, USA). Superoxide dismutase (SOD), catalase (CAT), xanthine oxidase, $\beta$-nicotinamide adenine dinucleotide 2'phosphate (NADPH), glutathione reductase (GR), reduced glutathione (GSH), malondialdehyde (MDA), thiobarbituric acid (TBA), L-aspartate, L-alanine, and $\alpha$ ketoglutarate were also purchased from SigmaAldrich Chemical. Absolute ethanol and gallic acid were purchased from Merck (Darmstadt, Germany). Ascorbic acid was obtained from Rankem (New Delhi, India). Dulbecco's modified Eagle medium (DMEM, Cat. No. 11885-084), Dulbecco's modified Eagle medium nutrient mixture F-12 (DMEM/F-12 without phenol red, Cat. No. 21041-025), and fetal bovine serum (FBS) were purchased from Gibco (New York, USA). All other laboratory chemicals were of the highest purity and were obtained from chemical suppliers.

\section{Induction of oxidative stress}

HepG2 cells (HB-8065) were purchased from ATCC (Manassas, Virginia, USA) and cultured in DMEM supplemented with $10 \%$ FBS, Glutamax ${ }^{\circledR}$, penicillin, and streptomycin under 95 $\%$ humidity in an atmosphere of $5 \% \mathrm{CO}_{2}$ at 37 ${ }^{\circ} \mathrm{C}$. The cells were cultured in DMEM in a 6-well plate $\left(5 \times 10^{5}\right.$ cells/well). The medium was discarded after $48 \mathrm{~h}$, and the cells were washed with $1 \times \mathrm{PBS}$ and replaced with DMEM/F-12 without phenol red supplemented with $10 \%$ FBS, Glutamax ${ }^{\circledR}$, penicillin, and streptomycin containing ethanol, sodium selenite, or TBHP at various concentrations and incubated for various intervals: ethanol was used at 10, 100, and 500 $\mathrm{mM}$ and sodium selenite at 1,5 , and $10 \mu \mathrm{M}$ for 24 or 48 h; TBHP was used at 50, 100, and 200 $\mu \mathrm{M}$ for 3 or $24 \mathrm{~h}$ if not otherwise indicated. The control was incubated with DMEM/F-12 $[8,9]$.

\section{Determination of lactate dehydrogenase (LDH) activity}

The toxicity of ethanol, sodium selenite, and TBHP was assessed in culture medium using an LDH Assay Kit $\left(\right.$ Sigma $\left.{ }^{\circledR}\right)$. The percentage of toxicity was calculated based on LDH activity by comparison with $2 \%(\mathrm{v} / \mathrm{v})$ Triton X-100.

Determination of aspartate aminotransferase (AST) and alanine aminotransferase (ALT) levels

The culture medium was incubated with AST ( $L$ aspartate and $\alpha$-ketoglutarate) or ALT ( $L$-alanine and $\alpha$-ketoglutarate) substrates at $37^{\circ} \mathrm{C}$ for 30 or $20 \mathrm{~min}$, respectively, and DNPH was added for 20 min before the addition of $4 \mathrm{~N} \mathrm{NaOH}$. Absorbance was measured at a wavelength of $505 \mathrm{~nm}$. Aspartate aminotransferase (AST) and alanine aminotransferase (ALT) levels were expressed as international units per liter (IU/L) by comparison with a standard curve of sodium pyruvate [11].

\section{Determination of lipid peroxidation by the thiobarbituric acid reactive substances (TBARS) assay}

HepG2 cell homogenate was mixed with $10 \%$ trichloroacetic acid (TCA) followed by centrifugation at $2,300 \times \mathrm{g}$ at $4{ }^{\circ} \mathrm{C}$ for $10 \mathrm{~min}$. The supernatant was pipetted to a new tube, and 0.8 $\%$ TBA was added before boiling at $100{ }^{\circ} \mathrm{C}$ for 15 min, followed by immediate cooling. The MDA in the supernatant was measured by 
spectrofluorometry at excitation and emission wavelengths of 520 and $590 \mathrm{~nm}$, respectively, and by comparison with the standard curve of MDA [12].

\section{Determination of superoxide dismutase (SOD) activity}

HepG2 cell homogenate was mixed with chloroform and ethanol (1:1.67) before centrifugation at $14,000 \times \mathrm{g}$ at $4{ }^{\circ} \mathrm{C}$ for $30 \mathrm{~min}$. The supernatant was incubated with a reaction mixture containing $0.6 \quad \mathrm{mM}$ ethylenediaminetetraacetic acid (EDTA), $3 \mathrm{mM}$ xanthine, $3 \mathrm{mM} \mathrm{NBT}, 400 \mathrm{mM} \mathrm{Na}_{2} \mathrm{CO}_{3}$, and $1 \mathrm{~g} / \mathrm{L}$ bovine serum albumin (BSA) at $25^{\circ} \mathrm{C}$ for $20 \mathrm{~min}$, followed by the addition of xanthine oxidase. After incubation, $0.8 \mathrm{mM} \mathrm{CuCl}_{2}$ was added. Absorbance was measured at a wavelength of $550 \mathrm{~nm}$ and converted to SOD activity by comparison with an SOD standard [12].

\section{Determination of catalase (CAT) activity}

HepG2 cell homogenate was incubated with 130 $\mu \mathrm{M} \mathrm{H} \mathrm{O}_{2}$ at $37{ }^{\circ} \mathrm{C}$ for $1 \mathrm{~min}$. The reaction was terminated by the addition of $32.4 \mathrm{mM}$ ammonium molybdate, followed by absorbance measurement at a wavelength of $405 \mathrm{~nm}$. The CAT activity was determined by comparison with a CAT standard [12].

\section{Assessment of the total glutathione (GSH) content}

HepG2 cell homogenate was mixed with a mixture of $0.01 \mathrm{M}$ potassium phosphate buffer (pH 7.0), GR, and $1.5 \mathrm{mg} / \mathrm{mL}$ DTNB, followed by the addition of $0.16 \mathrm{mg} / \mathrm{mL} \mathrm{NADPH}$. The absorbance at a wavelength of $405 \mathrm{~nm}$ was recorded every $30 \mathrm{~s}$ for $10 \mathrm{~min}$. The total GSH content was calculated by comparison with the slope of the GSH standard curve [12].

\section{Statistical analysis}

The results are expressed as the mean \pm SD. All data were statistically analyzed using one-way analysis of variance (ANOVA) followed by Tukey's post hoc test. $p<0.05$ was considered statistically significant.

\section{RESULTS}

\section{Effects of ethanol, sodium selenite, and TBHP on HepG2 cell cytotoxicity}

The LDH activity over 10 is considered cytotoxic [13]. No cytotoxicity was observed in the treatment of HepG2 cells with ethanol $(10,100$, and $500 \mathrm{mM}$ ) for $24 \mathrm{~h}$, although treatment for 48 $h$ at the two higher concentrations resulted in significant cytotoxicity (Figure 1 A). In contrast, significant cytotoxicity was observed after treating HepG2 cells with sodium selenite $(1,5$, and $10 \mu \mathrm{M}$ ) for 24 and $48 \mathrm{~h}$ (Figure $1 \mathrm{~B}$ ) and with $\operatorname{TBHP}(50,100$, and $200 \mu \mathrm{M})$ for 3 and $24 \mathrm{~h}$ (Figure $1 \mathrm{C}$ ). These observations suggest that compared with sodium selenite and ethanol, TBHP has the highest toxic potential due to the minimal time required to induce cytotoxicity.
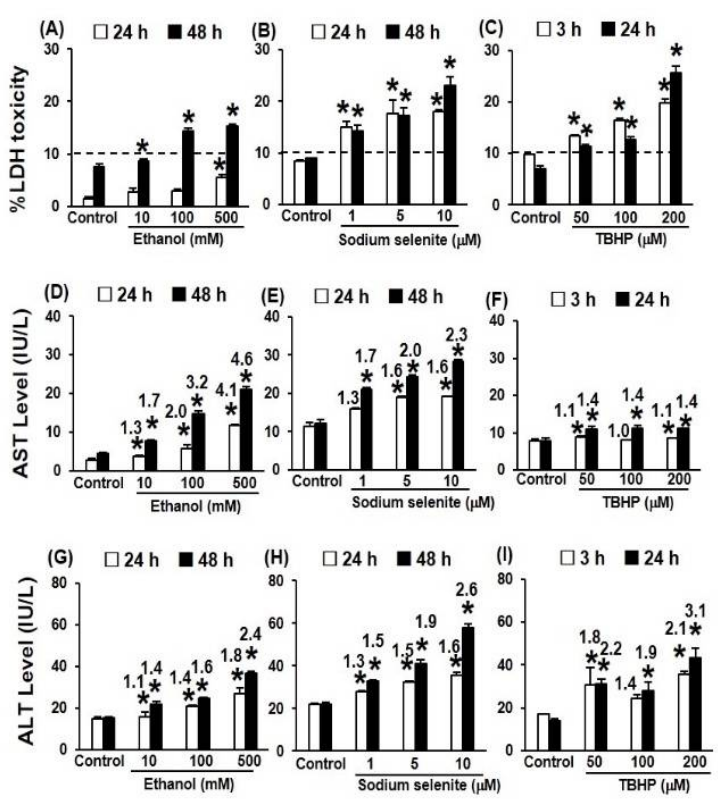

Figure 1: Effects of ethanol, sodium selenite, and TBHP on HepG2 cell cytotoxicity. A-C) The percentage of LDH activity, D-F) AST level, and G-I) ALT level. ${ }^{*} p<0.05$ vs controls with the same treatment interval

Both AST and ALT levels were significantly increased using all concentrations of ethanol at both 24 and $48 \mathrm{~h}$ (Figure $1 \mathrm{D}$ and G). Similarly, all concentrations of sodium selenite significantly increased the levels of these biomarker enzymes at both 24 and $48 \mathrm{~h}$ (Figure $1 \mathrm{E}$ and $\mathrm{H}$ ). However, treatments with all concentrations of TBHP for $3 \mathrm{~h}$ elevated AST levels only slightly, with higher increases after treatment for $24 \mathrm{~h}$ (Figure $1 \mathrm{~F}$ ). The levels of ALT were significantly increased by TBHP at both 3 and $24 \mathrm{~h}$ (Figure 1 I). These results reveal that ethanol and sodium selenite cause concentration- and timedependent increases in AST and ALT levels but TBHP shows only a time-dependent effect.

Effects of ethanol, sodium selenite, and TBHP on cellular antioxidant system

Oxidative stress is indicated by decreases in SOD and CAT activities, including the depletion of total GSH [5]. Exposing HepG2 cells to 
ethanol (Figure 2A, 2D, and 2G) and sodium selenite (Figure 2B, 2E, and $2 \mathrm{H}$ ) for 24 and $48 \mathrm{~h}$ and to TBHP for 3 and $24 \mathrm{~h}$ (Figure $2 \mathrm{C}, \mathrm{F}$, and I) resulted in significant dose- and timedependent decreases in SOD and CAT activities as well as in the total GSH content.

MDA is the end product of lipid peroxidation, and its level indicates cell damage [20]. Treating HepG2 cells with ethanol (Figure 2J) and sodium selenite (Figure $2 \mathrm{~K}$ ) for 24 and $48 \mathrm{~h}$ and TBHP (Figure $2 \mathrm{~L}$ ) for 3 and $24 \mathrm{~h}$ significantly elevated MDA levels in a dose- and time-dependent manner. These observations suggest that TBHP is the strongest oxidative stressor due to its ability to disrupt the oxidant-antioxidant balance, decrease SOD and CAT activities, and deplete total GSH with an increase in MDA within $3 \mathrm{~h}$.

\section{Effects of ascorbic acid and gallic acid on cytotoxicity and cellular antioxidant system}

Ascorbic acid at $25-100 \mu \mathrm{M}$ and gallic acid at 29 - $294 \mu \mathrm{M}$ were not toxic to HepG2 cells. The oxidative stressors ethanol, sodium selenite, and TBHP caused cytotoxicity in HepG2 cells, and cotreatment with either ascorbic acid or gallic acid indicated a tendency to ameliorate LDH toxicity to the cells (Figure $3 \mathrm{~A}$ ).
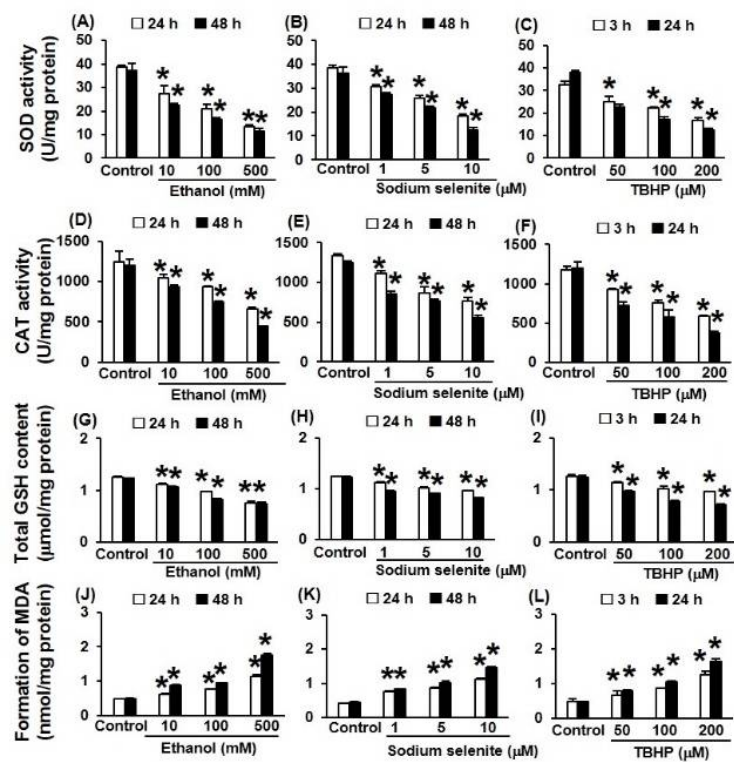

Figure 2: Effects of ethanol, sodium selenite, and TBHP on the cellular antioxidant system in HepG2 cells. A-C) SOD activity, D-F) CAT activity, G-I) total GSH content, and J-L) MDA level; ${ }^{*} p<0.05$ vs controls with the same treatment interval

In addition, the levels of AST and ALT in HepG2 cells were undisturbed by ascorbic acid and gallic acid, whereas ethanol, sodium selenite, and TBHP significantly increased the levels of both enzymes (Figure $3 \mathrm{~B}$ and $\mathrm{C}$ ). Coadministering antioxidants (either ascorbic acid or gallic acid) with oxidative stressors (ethanol, sodium selenite, or TBHP) significantly reduced both AST and ALT levels in HepG2 cells.
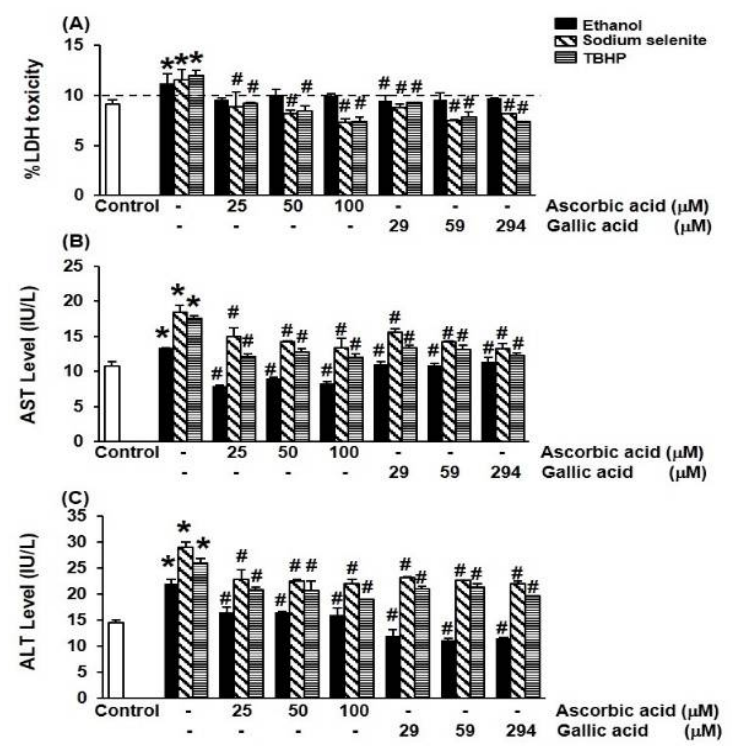

Figure 3: Effects of ascorbic acid and gallic acid on cytotoxicity in ethanol-, sodium selenite-, and TBHPinduced oxidative stress in HepG2 cell models. A) The percentage of LDH activity, B) AST level, and C) ALT level. ${ }^{*} p<0.05$ vs the controls; ${ }^{\#} p<0.05$ vs treatment with ethanol, sodium selenite, or TBHP alone

Ethanol, sodium selenite, and TBHP significantly reduced cellular SOD (Figure $4 \mathrm{~A}$ ) and CAT (Figure $4 \mathrm{~B}$ ) activities followed by depletion of total GSH (Figure $4 \mathrm{C}$ ). Ascorbic acid and gallic acid markedly increased cellular antioxidant parameters, namely, SOD and CAT activities and the total GSH content.

Neither ascorbic acid nor gallic acid changed the MDA level in HepG2 cells but the MDA levels were significantly increased after treatment with ethanol, sodium selenite, and TBHP for $24 \mathrm{~h}$ (Figure $4 \mathrm{D}$ ). When HepG2 cells were treated with ethanol, sodium selenite, and TBHP in combination with ascorbic acid and gallic acid for $24 \mathrm{~h}$, a significant decrease in the MDA level was observed. These findings support the approach of inducing oxidative stress in HepG2 cells using ethanol, sodium selenite, and TBHP and reveal the protective antioxidant potential of ascorbic acid and gallic acid against oxidative stress in these HepG2 cell models.

\section{DISCUSSION}

Excessive production of ROS leads to cellular injury, causing cell membrane rupture and loss of selective membrane permeability, which result in 

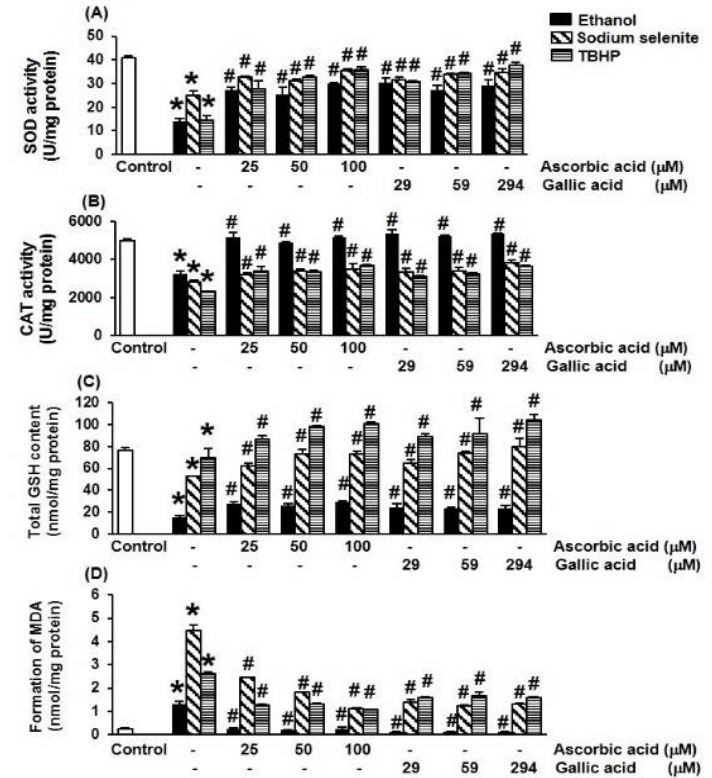

Figure 4: Effect of ascorbic acid and gallic acid on the cellular antioxidant system in ethanol-, sodium selenite-, and TBHP-induced oxidative stress in HepG2 cell models. A) SOD activity, B) CAT activity, C) total GSH content, and D) MDA level. * $p<0.05$ vs the controls; ${ }^{\#} p<0.05$ vs treatment with ethanol, sodium selenite, or TBHP alone

leakage of $\mathrm{LDH}, \mathrm{AST}$, and ALT into the extracellular space $[14,15]$.

Antioxidants are composed of two components, one of which involves major biochemical defense enzymes, such as SOD and CAT. The first mechanism of defense against free radical is SOD which transforms superoxide anion $\left(\mathrm{O}_{2}{ }^{\circ}\right)$ to hydrogen peroxide $\left(\mathrm{H}_{2} \mathrm{O}_{2}\right)$, followed by CAT, which catalyzes $\mathrm{H}_{2} \mathrm{O}_{2}$ to water and oxygen [5]. The other component is a non-enzymatic GSH system that is mostly synthesized in the liver. The predominant mechanism of GSH against free radicals is that it acts as a hydrogen or electron donor in detoxification [16]. In the present study, all oxidative stressors injured HepG2 cells via several pathways leading to the release of $L D H, A S T$, and ALT, elevation in the TBARS levels, decreases in SOD and CAT activities and the depletion of total GSH content.

Alcohol dehydrogenase (ADH) is the main enzyme that metabolizes ethanol to acetaldehyde, which is subsequently converted by aldehyde dehydrogenase to acetate, a molecule that is toxic to organs and to systemic circulation [17]. The microsomal ethanol oxidation system (MEOS) and CAT contribute to the metabolism of ethanol, including the production of ROS [18]. These results were consistent with those of a previous study showing that ethanol at a dose of $50 \mathrm{mM}$ for $24 \mathrm{~h}$ resulted in decreases in SOD and CAT activities and GSH content and an increase in MDA levels in HepG2 cells [19]. Yao et al. (2007) reported that ethanol at a dose of $100 \mathrm{mM}$ for $24 \mathrm{~h}$ increased the AST, LDH, and MDA levels with a decrease in the GSH level in human hepatocytes [9]. In this study, ethanol concentrations up to $500 \mathrm{mM}$ were used to treat HepG2 cells to demonstrate a change in the cellular antioxidant system.

Sodium selenite is a dietary form of selenium, but it is classified as a toxic compound. The hepatic glutathione system converts sodium selenite to selenium and consequently produces ROS, mainly $\mathrm{O}_{2}{ }^{-*}$ and $\mathrm{H}_{2} \mathrm{O}_{2}$. Although selenium is an essential element, previous studies have suggested that selenium from the metabolism of sodium selenite influences oxidative stressrelated cytotoxicity in HepG2 cells [8]. In accordance with this study, a previous study demonstrated a decrease in GSH content and LDH leakage in HepG2 cells treated with $10 \mu \mathrm{M}$ sodium selenite for $24 \mathrm{~h}$ [7]. Furthermore, treatment with sodium selenite at concentrations ranging from 5 to $25 \mu \mathrm{M}$ for $24 \mathrm{~h}$ resulted in an increase in LDH leakage and ROS production and a decrease in GSH content in HepG2 cells [8].

A short-chain organic hydroperoxide used as a bleaching and oxidizing agent in polymerization in industrial processes is TBHP [20]. In the liver, TBHP is metabolized via cytochrome P450 2E1, which consequently generates ROS, mainly peroxyl and alkoxyl, and leads to the initiation of oxidative stress [6]. Alternatively, TBHP is converted by the glutathione system to tert-butyl alcohol and glutathione disulfide, resulting in glutathione depletion [5]. In previous studies, the treatment of HepG2 cells with a dose of TBHP greater than $50 \mu \mathrm{M}$ for $3 \mathrm{~h}$ elevated the TBARS level and decreased SOD and CAT activities [21]. In addition, HepG2 cells treated with 200 $\mu \mathrm{M}$ TBHP for $3 \mathrm{~h}$ showed a decrease in GSH content with a reduction in SOD and CAT activities, followed by an increase in MDA level and LDH leakage [21]. Oxidative stress was observed in HepG2 cells after treatment with 250 $\mu \mathrm{M}$ TBHP for $3 \mathrm{~h}$. The viability of TBHP-treated HepG2 cells was $47.33 \%$, indicating cell growth suppression, which is related to increases in ROS and MDA production along with GSH depletion [22].

The present observations suggest that the cellular oxidant-antioxidant system in HepG2 cells was impaired by the excessive production of ROS due to the metabolism of ethanol, sodium selenite, and TBHP, resulting in oxidative stress. However, the potency of each substances to 
induce oxidative stress was not equivalent, and the concentration and time of incubation are important factors. As it requires the shortest exposure time, TBHP might be the strongest oxidative stressor. Further study of these three compounds was carried out to assure an efficient oxidative stress model. Ethanol, sodium selenite, and TBHP were evaluated in combination with ascorbic acid and gallic acid, both of which are known as strong natural antioxidants.

Structures of gallic acid and ascorbic acid contain several hydroxyl groups, which are important in direct reactions with free radicals and exhibit a potent radical-scavenging effect [23] via a hydrogen- or an electron-donating mechanism to eliminate an unpaired electron and neutralize free radicals [24]. In this study, oxidative stress was observed in HepG2 cells treated with ethanol, sodium selenite, and TBHP. Suppression of SOD and CAT activities and depletion of total GSH in HepG2 cells occurred. Ascorbic acid and gallic acid sustain the intracellular antioxidant system via electrondonating mechanisms and terminate the oxidative chain reaction, resulting in the inhibition of either initial or continued oxidative stress [25]. Consequently, both compounds were able to restore SOD and CAT activities and reverse the depletion of the total GSH content. These observations support these oxidative stress models as efficient systems for further study of the antioxidant activity of chemical/natural antioxidants.

\section{CONCLUSION}

In this study, ethanol-, sodium selenite-, and TBHP-induced oxidative stress models in HepG2 cells have been established. Though the required concentration of TBHP $(100 \mu \mathrm{M})$ is higher than that of sodium selenite $(10 \mu \mathrm{M})$, it exerts the strongest oxidative stimulus, requiring the minimal time $(3 h)$ to induce oxidative stress. Even ethanol acts as a mild oxidative stressor and might be the most relevant compound for daily exposure. Hence, to better understand the occurrence of chronic disease-associated oxidative stress, ethanol $(100 \mathrm{mM}, 24 \mathrm{~h})$ is an optimal oxidative stressor. Nonetheless, as these oxidative stressors differ in their generation of ROS and involvement in oxidative pathways, a given oxidative stressor should be carefully considered when choosing the optimal stressor to ultimately draw a precise evaluation.

\section{DECLARATIONS}

\section{Acknowledgements}

This work was supported by Research Group for Pharmaceutical Activities of Natural Products using Pharmaceutical Biotechnology, Faculty of Pharmaceutical Sciences, Khon Kaen University, Thailand under Grant PANPB2561. Yollada Sriset acknowledges the Graduate School, Khon Kaen University for scholarship (no. 601H215).

\section{Conflict of interest}

No conflict of interest is associated with this study.

\section{Contribution of authors}

The authors declare that this work was done by the authors named in this article and that all liabilities pertaining to claims relating to the content of this article will be borne by them. Yollada Sriset performed the experimental work and statistical analysis, prepared the figures, and drafted the manuscript. Waranya Chatuphonprasert planned the experimental work, verified the data, supervised the whole study, and revised the manuscript. Kanokwan Jarukamjorn designed the study, participated in the conceptual discussion, and revised the manuscript. The manuscript was thoroughly read and approved by all the authors for publication.

\section{Open Access}

This is an Open Access article that uses a funding model which does not charge readers or their institutions for access and distributed under the terms of the Creative Commons Attribution License (http://creativecommons.org/licenses/by/ 4.0) and the Budapest Open Access Initiative (http://www.budapestopenaccessinitiative.org/rea d), which permit unrestricted use, distribution, and reproduction in any medium, provided the original work is properly credited.

\section{REFERENCES}

1. Jaeschke $H$, Gores GJ, Cederbaum Al, Hinson JA, Pessayre D, Lemasters JJ. Mechanisms of hepatotoxicity. Toxicol Sci 2002; 65(2): 166-176.

2. Valko M, Rhodes CJ, Moncol J, Izakovic M, Mazur M. Free radicals, metals and antioxidants in oxidative stress-induced cancer. Chem Biol Interact 2006; 160(1): $1-40$. 
3. Birben E, Sahiner UM, Sackesen C, Erzurum S, Kalayci O. Oxidative stress and antioxidant defense. World Allergy Organ J 2012; 5(1): 9-19.

4. Limón-Pacheco J, Gonsebatt ME. The role of antioxidants and antioxidant-related enzymes in protective responses to environmentally induced oxidative stress. Mutat Res 2009; 674(1-2): 137-147.

5. Lin WL, Wang CJ, Tsai YY, Liu CL, Hwang JM, Tseng $T H$. Inhibitory effect of esculetin on oxidative damage induced by t-butyl hydroperoxide in rat liver. Arch Toxicol 2000; 74(8): 467-472.

6. Liu CL, Wang JM, Chu CY, Cheng MT, Tseng TH. In vivo protective effect of protocatechuic acid on tert-butyl hydroperoxide-induced rat hepatotoxicity. Food Chem Toxicol 2002; 40(5): 635-641.

7. Shen HM, Yang C, Liu J, Ong C. Dual role of glutathione in selenite-induced oxidative stress and apoptosis in human hepatoma cells. Free Radic Biol Med 2000; 28(7): 1115-1124.

8. Shen HM, Yang CF, Ong CN. Sodium selenite-induced oxidative stress and apoptosis in human hepatoma HepG2 cells. Int J Cancer 1999; 81(5): 820-828.

9. Yao P, Nussler A, Liu L, Hao L, Song F, Schirmeier A, Nussler N. Quercetin protects human hepatocytes from ethanol-derived oxidative stress by inducing heme oxygenase-1 via the MAPK/Nrf2 pathways. J Hepatol 2007; 47(2): 253-261.

10. Wilkening S, Stahl F, Bader A. Comparison of primary human hepatocytes and hepatoma cell line HepG2 with regard to their biotransformation properties. Drug Metab Dispos 2003; 31(8): 1035-1042.

11. Jarukamjorn K, Chatuphonprasert W, Jearapong $N$, Punvittayagul C, Wongpoomchai R. Tetrahydrocurcumin attenuates phase I metabolizing enzyme-triggered oxidative stress in mice fed a high-fat and high-fructose diet. J Funct Foods 2019; 55: 117-125.

12. Jearapong $N$, Chatuphonprasert $W$, Jarukamjorn $K$. Miroestrol, a phytoestrogen from Pueraria mirifica, improves the antioxidation state in the livers and uteri of $\beta$-naphthoflavone-treated mice. J Nat Med 2014; 68(1): 173-180.

13. Kendig DM, Tarloff JB. Inactivation of lactate dehydrogenase by several chemicals: Implications for in vitro toxicology studies. Toxicol In Vitro 2007; 21(1): 125-132.
14. Ozer J, Ratner M, Shaw M, Bailey W, Schomaker S. The current state of serum biomarkers of hepatotoxicity. Toxicology 2008; 245(3): 194-205.

15. Niki E, Yoshida Y, Saito Y, Noguchi N. Lipid peroxidation: mechanisms, inhibition, and biological effects. Biochem Biophys Res Commun 2005; 338(1): 668-676.

16. Caciatore I, Cornacchia C, Pinnen F, Mollica A, Di Stefano A. Prodrug approach for increasing cellular glutathione levels. Molecules 2010; 15(3): 1242-1264.

17. Zakhari S. Alcohol metabolism and epigenetics changes. Alcohol Res 2013; 35(1): 6-17.

18. Sid B, Verrax J, Calderon PB. Role of oxidative stress in the pathogenesis of alcohol-induced liver disease. Free Radic Res 2013; 47(11): 894-904.

19. Gutierrez-Ruiz MC, Gomez Quiroz LE, Hernandez E, Bucio L, Souza V, Llorente L, Kershenobich D. Cytokine response and oxidative stress produced by ethanol, acetaldehyde and endotoxin treatment in HepG2 cells. Isr Med Assoc J 2001; 3(2): 131-136.

20. Drahota $Z$, Kriváková $P$, Cervinková $Z$, Kmonícková E, Lotková H, Kucera O, Houstek J. Tert-butyl hydroperoxide selectively inhibits mitochondrial respiratory-chain enzymes in isolated rat hepatocytes. Physiol Res 2005; 54(1): 67-72.

21. Alia M, Ramos S, Mateos R, Bravo L, Goya L. Response of the antioxidant defense system to tert-butyl hydroperoxide and hydrogen peroxide in a human hepatoma cell line (HepG2). J Biochem Mol Toxicol 2005; 19(2): 119-128.

22. Sohn JH, Han KL, Lee SH, Hwang JK. Protective effects of panduratin $A$ against oxidative damage of tertbutylhydroperoxide in human HepG2 cells. Biol Pharm Bull 2005; 28(6): 1083-1086.

23. Flora SJS. Structural, chemical and biological aspects of antioxidants for strategies against metal and metalloid exposure. Oxid Med Cell Longev 2009; 2(4): 191-206.

24. Reckziegel P, Dias VT, Benvegnú DM, Boufleur N, Barcelos RCS, Segat HJ, Pase CS, Dos Santos CMM, Flores ÉMM, Bürger ME. Antioxidant protection of gallic acid against toxicity induced by $\mathrm{Pb}$ in blood, liver and kidney of rats. Toxicol Rep 2016; 3: 351-356.

25. Mansouri MT, Naghizadeh B, Ghorbanzadeh B, Farbood Y, Sarkaki A, Bavarsad K. Gallic acid prevents memory deficits and oxidative stress induced by intracerebroventricular injection of streptozotocin in rats. Pharmacol Biochem Behav 2013; 111: 90-96. 